Check for updates

Cite this: RSC Adv., 2018, 8, 25835

\title{
Hot pressing-induced alignment of hexagonal boron nitride in SEBS elastomer for superior thermally conductive composites $\uparrow$
}

\author{
Cuiping $Y u^{\text {abc }}$ Wenbin Gong, ${ }^{\text {b Jun Zhang, }}{ }^{\text {b Weibang } L v,}{ }^{\text {b }}$ Wei Tian, ${ }^{\text {*a }}$ Xiaodong Fan ${ }^{a}$ \\ and Yagang Yao (iD)*bc
}

Styrene-ethylene-butylene-styrene (SEBS) composite films containing well-dispersed and highly aligned hexagonal boron nitride ( $\mathrm{hBN}$ ) platelets were achieved by a ball milling process followed by hot-pressing treatment. An ultrahigh in-plane thermal conductivity of $45 \mathrm{~W} \mathrm{~m}^{-1} \mathrm{~K}^{-1}$ was achievable in the SEBS composite film with $95 \mathrm{wt} \% \mathrm{hBN}$. The corresponding out-of-plane thermal conductivity was also as high as $4.4 \mathrm{~W} \mathrm{~m}^{-1} \mathrm{~K}^{-1}$. The hBN/SEBS composite film was further used to cool a CPU connected to a computer, resulting in a decrease by about $4{ }^{\circ} \mathrm{C}$ in the stable temperature. Percolation thresholds over $40 \mathrm{wt} \%$ and $60 \mathrm{wt} \%$ in the hBN/SEBS composites were obtained in the in-plane and out-of-plane directions, respectively. This phenomenon has rarely been reported in polymer composites. Molecular dynamics simulations were also conducted to support this percolation threshold. The linear coefficients of the thermal expansion value of the hBN/SEBS composite with $95 \mathrm{wt} \% \mathrm{hBN}$ was as low as $16 \mathrm{ppm} \mathrm{K} \mathrm{K}^{-1}$. This was a significant decrease compared to that of pure SEBS $\left(149 \mathrm{ppm} \mathrm{K}{ }^{-1}\right)$. The proposed strategy provides valuable advice about the heat-transfer mechanism in polymer composites containing oriented

two-dimensional materials.

Received 1st June 2018

Accepted 5th July 2018

DOI: $10.1039 / \mathrm{c} 8 \mathrm{ra0} 4700 \mathrm{f}$

rsc.li/rsc-advances

\section{Introduction}

Thermally conductive while electrically insulating polymerbased composite films are highly desirable for their applications in aircraft, motor control, automobiles, and household applications because of their wide range of utilization, ease of processing, and low cost. ${ }^{1,2}$ However, the thermal conductivity of current polymer-based composites is below $10 \mathrm{~W} \mathrm{~m}^{-1} \mathrm{~K}^{-1}$, and so hardly able to satisfy the growing demand for highperformance materials. ${ }^{3-5}$ Therefore, there is an urgent need to develop a new strategy to prepare desired materials with high thermal conductivity. Inorganic fillers, such as aluminum nitride, ${ }^{6,7}$ alumina,${ }^{8,9}$ or boron nitride,$^{1-5,10-17}$ have been added to

\footnotetext{
${ }^{a}$ The Key Laboratory of Space Applied Physics and Chemistry, Ministry of Education and Shaanxi Key Laboratory of Macromolecular Science and Technology, School of Science, Northwestern Polytechnical University, Xi'an 710072, PR China. E-mail: happytw_3000@nwpu.edu.cn

${ }^{b}$ Division of Advanced Nanomaterials, Key Laboratory of Nanodevices and Applications, Joint Key Laboratory of Functional Nanomaterials and Devices, CAS Center for Excellence in Nanoscience, Suzhou Institute of Nano-tech and Nanobionics, Chinese Academy of Sciences, Suzhou 215123, PR China. E-mail: ygyao2013@sinano.ac.cn

'Division of Nanomaterials, Suzhou Institute of Nano-Tech and Nano-Bionics, Chinese Academy of Sciences, Nanchang 330200, PR China

$\dagger$ Electronic supplementary information (ESI) available. See DOI: $10.1039 / \mathrm{c} 8 \mathrm{ra} 04700 \mathrm{f}$
}

polymer matrices to improve the thermal performance because of their high thermal conductivity and electric insulation.

Hexagonal boron nitride (hBN), also called white graphite, has attracted much attention due to its high thermal conductivity, relatively lower density, and a large band gap (nearly 5.9 $\mathrm{eV}$ ), which make it suitable for applications in thermally conductive and insulating composites. ${ }^{1-4,10,13,18,19}$ In recent years, much effort has been directed to the rational design and controlled preparation of hBN-filled polymer composites. ${ }^{1,3-5,13,20-24}$ As reported previously, the thermal property of hBN-filled composites is mainly influenced by the interface and dispersion state of hBN in polymer composites. ${ }^{1,4,5,20-23,25,26}$ The interface is mainly influenced by the compatibility between the fillers and matrix. Modification by hBN can enhance the affinity of the hBN/polymer interface. This is an efficient strategy to optimize the thermal conductivity of composites via reducing the interfacial thermal resistance. ${ }^{21,25}$ For example, Gu et al. fabricated polyhedral oligomeric silsesquioxane (POSS)functionalized hBN. The as-made POSS-hBN was filled into bismaleimide/diallylbisphenol $\mathrm{A}^{27}$ and polyphenylene sulfide ${ }^{28}$ to improve the thermal conductivity. Besides, designing a new polymer matrix is beneficial for increasing the combination between hBN fillers and the matrix. For example, thiol-epoxy elastomers ${ }^{29}$ and bisphenol A dicyanate ester/dicyclopentadiene bisphenol cyanate ester hybrid resin ${ }^{30}$ were fabricated and the composites were endowed with excellent thermal conductivity. However, the modification unavoidably destroyed the crystal 
structure of hBN and reduced its thermal performance. Also, the fabrication process was complex due to the introduction of many monomers, which limited its uses in practical applications. In addition, the enhancement efficiency was still low. To reach a high thermal conductivity, a high hBN loading is necessary due to the construction of more thermally conductive channels of hBN.,31 Therefore, it is desirable to develop a strategy to reach a high filler loading.

Besides, since hBN exhibits an in-plane thermal conductivity of $600 \mathrm{~W} \mathrm{~m} \mathrm{~m}^{-1} \mathrm{~K}^{-1}$, almost 20 times higher than that of the through-plane thermal conductivity, ${ }^{20}$ it is widely accepted that a significant enhancement in the in-plane thermal conductivity could be achieved by controlling the alignment of hBN via enabling the constructing of heat conductive networks. Therefore, it is desirable to develop a novel, facile, straightforward strategy to fabricate hBN-filled composites with a highly aligned structure. Recently, many novel methods have been reported to assist the orientation, including doctor blading, ${ }^{21}$ magnetic field alignment, ${ }^{22,23}$ oscillatory shearing, ${ }^{5}$ and electric field. ${ }^{26}$ However, these methods are just suitable for low filler loadings because a large amount of the hBN causes an increase in the viscosity, which interferes with the hBN orientation, albeit the proposed methods showed significant thermal conductivity enhancements. However, the thermal conductivity was marginal compared to that expected for systems with a high filler loading fraction, and still insufficient for the increasing demands for higher thermally conductive composites. Thus, a route to achieve high filler loading while maintaining the oriented structure is desirable to improve the thermal conductivity. To date, vacuum filtration has been shown to be able to achieve this goal. ${ }^{\mathbf{1 1 0}}$ For example, Zhu et al. fabricated an aligned boron nitride nanosheet (BNNS) paper wired by nanofibrillated cellulose. ${ }^{1}$ This paper exhibited an ultrahigh thermal conductivity of $145.7 \mathrm{~W} \mathrm{~m}^{-1} \mathrm{~K}^{-1}$ at $50 \mathrm{wt} \%$ BNNS loading. This could be ascribed to the gravity force brought about by vacuum filtration, which tended to horizontally orient the hBN microplatelets. $^{12,32,33}$ However, the size of the hBN paper under vacuum filtration was limited by the size of the funnel, making it difficult to produce larger sizes. Therefore, it is still challenging to design and obtain hBN-filled composite films at a large range of filler loadings via a facile and effective process in an oriented fashion.

In this work, we fabricated hBN/styrene-ethylene-butylenestyrene (SEBS) composite films with hBN aligned in parallel through a hot pressing-induced-alignment technique. SEBS was chosen as the matrix, because it is an elastomer that can be used without vulcanization and it resists high-temperature. This was beneficial for the hot-forming procedure. Since the composites were fabricated by solvent mixing, by which the concentrations of the dispersion could be precisely controlled, various filler loadings were designed (0-95 wt\%). The fabricated hBN/SEBS composites exhibited a superior thermal conductivity of $45 \mathrm{~W}$ $\mathrm{m}^{-1} \mathrm{~K}^{-1}$ at $95 \mathrm{wt} \% \mathrm{hBN}$ loading. Based on this aligned structure, the thermal conductivity was tested and analyzed by molecular dynamics simulations. This was constructive for exploring the heat-transfer mechanism of the composites containing oriented two-dimensional (2D) fillers.

\section{Experimental}

\section{Materials}

hBN powder (sizes ranging from $10 \mu \mathrm{m}$ to $30 \mu \mathrm{m}$, purity > 99.5\%) was purchased from Dandong Rijin Science and Technology Co., Ltd. (Liaoning, China). The SEBS used was Kraton G1652 (American). Tetrahydrofuran (THF) and ethanol were purchased from Sinopharm Chemical Reagent Co., Ltd. (Beijing, China). All the chemicals were analytical grade and were used as received without further treatments.

\section{Preparation of hBN/SEBS composite films}

SEBS matrix and hBN filler were dried under in a vacuum oven at $60{ }^{\circ} \mathrm{C}$ for at least $12 \mathrm{~h}$. A typical example of the preparation of $95 \mathrm{wt} \% \mathrm{hBN} / \mathrm{SEBS}$ composite film is as follows: $0.5 \mathrm{~g}$ dried SEBS was dispersed into $4.5 \mathrm{~g}$ THF by stirring for $3 \mathrm{~h}$ at $40{ }^{\circ} \mathrm{C}$ to obtain a SEBS solution with $10 \mathrm{wt} \% \mathrm{hBN}$. $9.5 \mathrm{~g}$ dried hBN powder was added into the SEBS solution. The hBN/SEBS solution was subjected to ball milling for $24 \mathrm{~h}$ in a planetary ball mill at a rotational speed of $400 \mathrm{rpm}$ at room temperature. This resulted in a homogeneous hBN/SEBS dispersion. A solid-state hBN/SEBS mixture was obtained after the dispersion was added to excessive ethanol. The coagulated polymer composites were then isolated via subsequent settlement and dried in a vacuum at $50{ }^{\circ} \mathrm{C}$ for $24 \mathrm{~h}$. The as-made hBN/SEBS mixtures were pressed between brass plates to form $0.1 \mathrm{~mm}$ thin films using $0.1 \mathrm{~mm}$ thick spacers in a hydraulic hot press at $150{ }^{\circ} \mathrm{C}$ under a pressure of $10 \mathrm{MPa}$ for $15 \mathrm{~min}$. Various mass fractions of hBN in the composites were achieved via controlling the feed ratio before the ball milling process.

\section{Molecular dynamics simulations}

Molecular dynamics simulations were performed via the largescale atomic/molecular dynamic package (LAMMPS), ${ }^{34}$ with a time step of $0.1 \mathrm{fs}$. The intramolecular interaction of the thermoplastic elastomer was described by its Airebo potential, ${ }^{35}$ while the Tersoff potential was used to simulate the $\mathrm{B}-\mathrm{N}$ bonds in $\mathrm{hBN}^{36}$ The intermolecular interaction between the thermoplastic elastomer and the hBN was described by the Lennard-Jones potential, and the intermolecular interaction of the hBN was modeled with the coulombic potential to obtain its ionic characteristic. The cutoff of these long-range interactions was set at $15 \AA$. The charges of the boron and the nitrogen atoms were calculated to be $-0.6 e$ and $0.6 e$ by charge equilibration calculations. The force-field settings are summarized in Table S1. $\dagger$ Several pieces of hBN were added into the thermoplastic elastomer matrix, which consisted of 22 SEBS chains with 1100 atoms in each molecule, to simulate different hBN contents. Beginning with a 20 ps running in the NVT ensemble at $300 \mathrm{~K}$, the equilibrium structures at a pressure of 10 atm were obtained within a $26.3 \times 156.6 \times 74.2 \AA^{3}$ simulation box, by performing 30 ps simulations in the NPT ensembles. The thermal conductivity calculations were then performed by equilibrating the structures at constant volume and temperature $(300 \mathrm{~K})$. This was followed by a $200 \mathrm{ps}$ run to 
establish a steady heat flux via the reverse non-equilibrium molecular dynamics method (rNEMD), as shown in Fig. S1. $\dagger^{37}$

\section{Characterization}

The sample morphologies were measured with scanning electron microscopy (SEM, SU8010, 2 kV). Thermogravimetric analysis (TGA) was performed on a thermogravimetric analyzer TG 209 F1 (NETZSCH, Germany) under air atmosphere with a heating rate of $10{ }^{\circ} \mathrm{C} \mathrm{min}{ }^{-1}$ from room temperature to $900{ }^{\circ} \mathrm{C}$. The thermal diffusivities $(\alpha)$ of the composite films were measured with a laser flash thermal analyzer (LFA 447, NETZSCH) with $12.7 \mathrm{~mm}$ diameter samples. The composites were sprayed with graphite powder on both sides before characterization. The thermal conductivity $(\lambda)$ was obtained with the equation $\lambda(T)=\alpha(T) \times C_{\mathrm{p}}(T) \times \rho(T)$. The densities $(\rho)$ of the composite films were calculated from the weight and dimensions of the composite films. The specific heat capacities $\left(C_{\mathrm{p}}\right)$ of the composites were measured by differential scanning calorimetry (DSC, 200 F3, NETZSCH, Germany). The thermal diffusivities, densities, and specific heats were all characterized at $25{ }^{\circ} \mathrm{C}$. The linear coefficient of thermal expansion (CTE) of the composites was measured using a thermomechanical analyzer (TMA, $402 \mathrm{~F} 3, \mathrm{NETZSCH}$ ) at a heating rate of $5 \mathrm{~K} \mathrm{~min}^{-1}$ to $80{ }^{\circ} \mathrm{C}$ in a nitrogen atmosphere. The tensile property was measured on the hydraulic universal material testing machine Instron 3365 (Instron Corporation, USA) with a cross-head speed of $2 \mathrm{~mm} \mathrm{~min}^{-1}$. The CPU used was an Intel® Pentium ${ }^{\circledR}$ CPU G4560 @ 3.5 GHz. The CPU output power was fixed at 60\%.

\section{Results and discussion}

Fig. 1a schematically exhibits the preparation process of the hBN/SEBS composite films via the ball milling process followed by the hot-pressing treatment. Wet ball milling was used in this process to disperse hBN in the SEBS solution. Compared to the traditional mixing strategy of mechanical stirring, ball milling had a better dispersion effect due to the shear force and compression force generated by balls of various diameters. The preparation process is shown in Fig. 1a, where a mixture of hBN and SEBS solution was ball milled in a grinding chamber. The obtained hBN/SEBS dispersion was precipitated in ethanol, resulting in hBN/SEBS coagulation solids. These were hot pressed to fabricate a freestanding, large-scale composite film (Fig. 1b). The SEM images of $95 \mathrm{wt} \% \mathrm{hBN} / \mathrm{SEBS}$ composite film depicted a well-packed layers configuration (Fig. 1c and d). The formation of this highly ordered structure was facilitated by the shear forces of the hot-pressing process and the rigidity of the $2 \mathrm{D}$ hBN. This structure makes a great contribution to the heat transferring in the in-plane direction. By controlling the solution concentration and hBN feeds, various filler loadings could be achieved.

The presence of SEBS in THF during the hBN dispersion step not only prevented hBN aggregating together but also helped maintain the perfect structure of the hBN. This was supported by the SEM image of hBN in the hBN/SEBS composites after ball milling (Fig. 2b). The hBN microplatelets were rarely damaged after the ball milling procedure. The sizes and thicknesses of $\mathrm{hBN}$ in the hBN/SEBS composites were in the range of 5-25 $\mu \mathrm{m}$ (Fig. 2b) and about 180-270 nm (Fig. 2c), respectively. These values were similar to the pristine hBN powders (Fig. 2a). The subsequent coagulation in ethanol led to hBN/SEBS solids with uniformly dispersed hBN, in which the newly obtained hBN was wrapped up by SEBS (Fig. 2d).

The representative SEM images are revealed in Fig. 3a-l. As shown in Fig. 3a, c, e, g, i and k, the surface morphologies of hBN/SEBS composites depicted an increased number of hBN with increasing the filler loadings. The hBN microplatelets on the composite surface were parallel to the polymer flow direction and were not curved even after the hot-pressing treatment. This could be ascribed to the superior stiffness of hBN. The detailed examinations about the orientation of hBN in the composites were verified by the cross-sectional SEM morphologies (Fig. 3b, d, f, h, j and l). hBN was highly aligned in all the samples. There were micrometer-wide gaps between the hBN sheets edges in the composites with loadings lower than $40 \mathrm{wt} \%$. However, an obvious hBN overlap was observed in the $60 \mathrm{wt} \% \mathrm{hBN} / \mathrm{SEBS}$ composites. With the further addition of hBN to $80 \mathrm{wt} \%$ and $95 \mathrm{wt} \%$, a tightly packed and layered structure was revealed in the corresponding cross-sectional SEM images. This structure facilitated the construction of heat-transfer networks, which are beneficial for heat conductivity. The unique layered arrangement of hBN in the matrix dramatically increased the thermal conductivity.

The hBN contents in the composite films were quantified by TGA measurements. The TGA curves of hBN, SEBS, hBN/SEBS composites with various hBN contents are shown in Fig. 4f. Pristine hBN powder exhibited almost no significant weight loss until $800{ }^{\circ} \mathrm{C}$. However, there were two significant drops in the weight loss curves of the composites. The first drop from about $250{ }^{\circ} \mathrm{C}$ to $400-500{ }^{\circ} \mathrm{C}$ should be ascribed to the decomposition of SEBS. The second obvious weight loss happened from 400$500{ }^{\circ} \mathrm{C}$ to about $600{ }^{\circ} \mathrm{C}$ and was assigned to the combustion of the residual carbon of SEBS in the air atmosphere. Up to this temperature, all the organic compounds were completely decomposed and volatilized. hBN contents could be obtained by the residual weight at $800{ }^{\circ} \mathrm{C}$ and were approximately $20 \mathrm{wt} \%$, $40 \mathrm{wt} \%, 60 \mathrm{wt} \%, 80 \mathrm{wt} \%$, and $95 \mathrm{wt} \%$. The corresponding weight loss temperature and $T_{\text {Heat resistance index }}\left(T_{\mathrm{HRI}}\right)^{38,39}$ values of the pristine SEBS and hBN/SEBS composites with various filler loadings are presented in Table 1 . The corresponding $T_{\text {HRI }}$ values of the hBN/SEBS composites were about $200{ }^{\circ} \mathrm{C}$, showing relatively high thermal stability. The $T_{\mathrm{HRI}}$ values of the $\mathrm{hBN} /$ SEBS composites were gradually enhanced with the increasing addition of hBN, presenting the improved thermal stabilities. This revealed that the addition of $\mathrm{hBN}$ was beneficial for the heat resistance of the hBN/SEBS composites. This could be ascribed to the relatively higher thermal conductivity of hBN compared to that of pure SEBS, which was apt to absorb the outside heat. Besides, hBN could effectively hinder the effusion of pyrolysis volatiles. Thus, the thermal stabilities of the hBN/ SEBS composites were improved accordingly.

$$
T_{\mathrm{HRI}}=0.49 \times\left[T_{5}+0.6 \times\left(T_{30}-T_{5}\right)\right]
$$


(a)
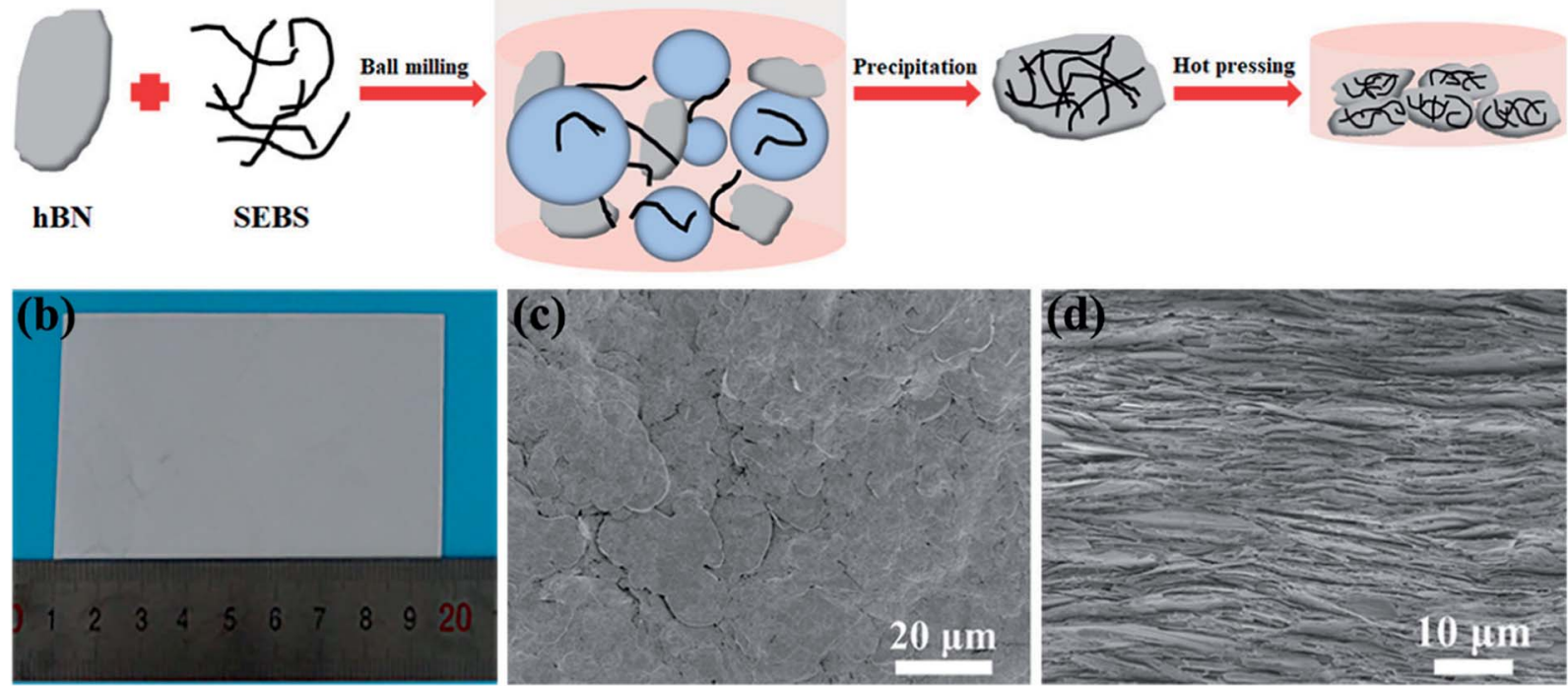

Fig. 1 (a) Schematic illustration of the fabrication process for the hBN/SEBS composite films. (b) Optical images of the large-scale 95 wt\% hBN/ SEBS composite film. Typical surface morphology (c) and cross-sectional morphology (d) of 95 wt\% hBN/SEBS composite film.

$T_{5}$ and $T_{30}$ are the corresponding decomposition temperatures of $5 \%$ and $30 \%$ weight loss, respectively.

The in-plane thermal conductivity of the hBN/SEBS composite film is shown in Fig. 4a. The thermal conductivity of the hBN/SEBS composite film increased to $4.4 \mathrm{~W} \mathrm{~m}^{-1} \mathrm{~K}^{-1}$ with $20 \mathrm{wt} \% \mathrm{hBN}$. This enhancement was significant compared to the pure SEBS film $\left(0.2 \mathrm{~W} \mathrm{~m}^{-1} \mathrm{~K}^{-1}\right)$. When the filler loadings were $30 \mathrm{wt} \%$ and $40 \mathrm{wt} \%$, the hBN/SEBS composite films exhibited thermal conductivity of about 5.2 and $6.7 \mathrm{~W} \mathrm{~m}^{-1} \mathrm{~K}^{-1}$, respectively. The thermal conductivity changed slightly at filler loadings from $20 \mathrm{wt} \%$ to $40 \mathrm{wt} \%$. However, the values were about $10 \mathrm{~W} \mathrm{~m}^{-1} \mathrm{~K}^{-1}$ and $15 \mathrm{~W} \mathrm{~m}^{-1} \mathrm{~K}^{-1}$ with $50 \mathrm{wt} \%$ and $60 \mathrm{wt} \%$
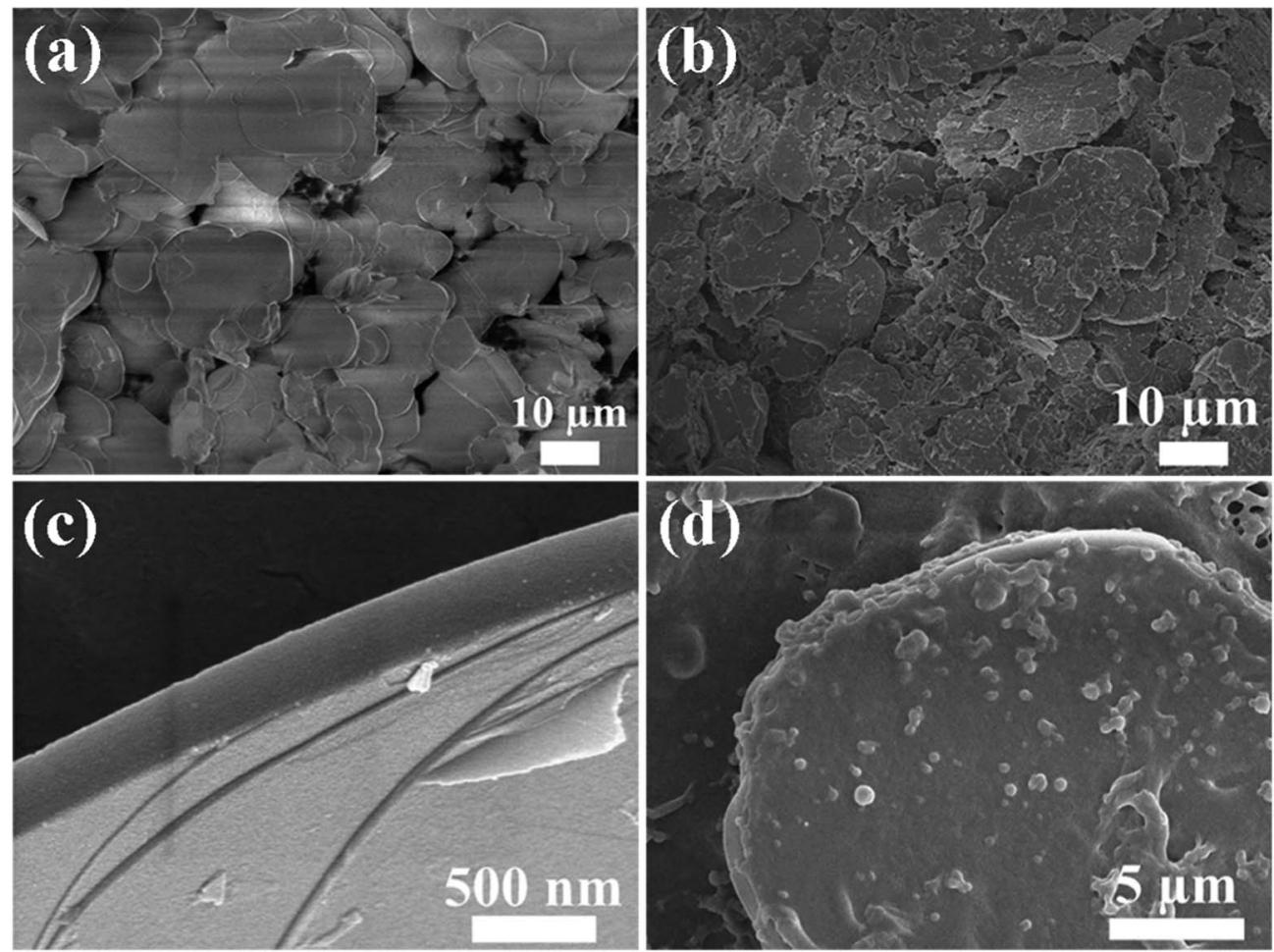

Fig. 2 SEM images of (a) pristine hBN powder, (b and d) hBN/SEBS coagulated solids, (c) hBN platelets in the hBN/SEBS coagulated solids. 

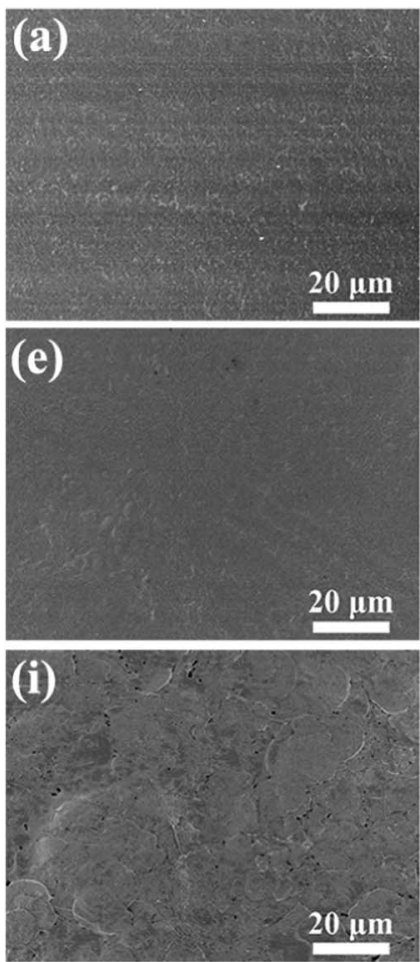
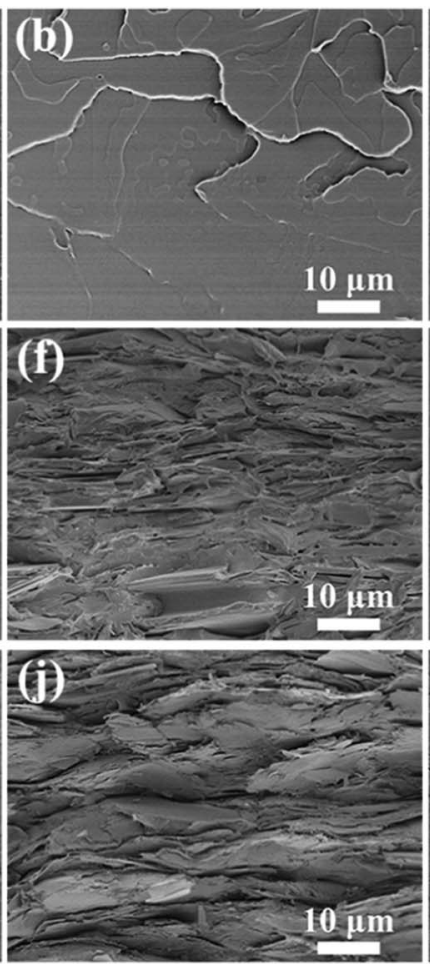
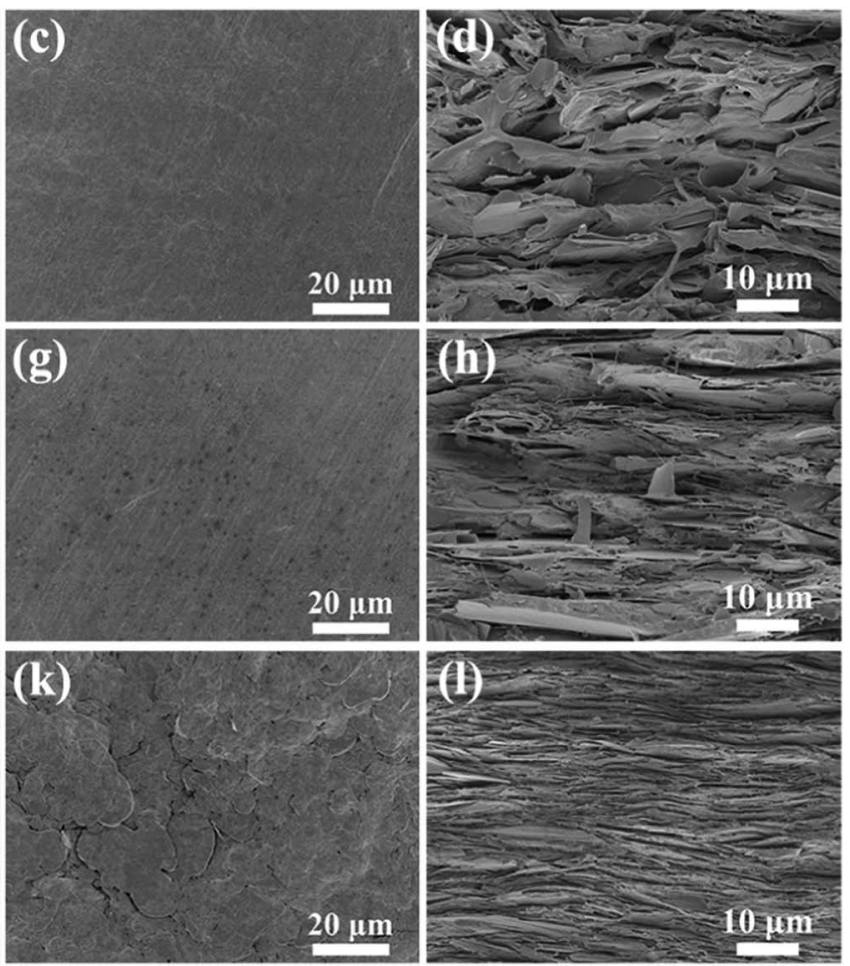

Fig. 3 SEM images of ( $a$ and b) SEBS, (c and d) 20 wt\% hBN/SEBS composite film, (e and f) 40 wt\% hBN/SEBS composite film, (g and h) 60 wt\% hBN/SEBS composite film, (i and j) 80 wt\% hBN/SEBS composite film, (k and l) 95 wt\% hBN/SEBS composite film; (a), (c), (e), (g), (i) and (k): surface morphologies; (b), (d), (f), (h), (j) and (l): cross-sectional morphologies.

hBN, respectively. This enhancement was very obvious compared to that of the composites with $20-40 \mathrm{wt} \% \mathrm{hBN}$. The thermal conductivity of the hBN/SEBS composite reached $27.5 \mathrm{~W} \mathrm{~m}^{-1} \mathrm{~K}^{-1}$ and $45 \mathrm{~W} \mathrm{~m}^{-1} \mathrm{~K}^{-1}$ when $80 \mathrm{wt} \%$ and $95 \mathrm{wt} \%$ hBN were added. Such excellent thermal conductivity was much higher than those of the hBN-filled composites (Fig. 4b). Fig. 4c exhibits the out-of-plane thermal conductivity of the hBN/SEBS composite films. The $20 \mathrm{wt} \% \mathrm{hBN} / \mathrm{SEBS}$ composite film exhibited a thermal conductivity of $0.4 \mathrm{~W} \mathrm{~m}^{-1} \mathrm{~K}^{-1}$. The hBN/ SEBS composite films showed thermal conductivities of $0.6 \mathrm{~W}$ $\mathrm{m}^{-1} \mathrm{~K}^{-1}, 0.8 \mathrm{~W} \mathrm{~m}^{-1} \mathrm{~K}^{-1}$, and $0.94 \mathrm{~W} \mathrm{~m}^{-1} \mathrm{~K}^{-1}$ when the hBN loadings were $30 \mathrm{wt} \%, 40 \mathrm{wt} \%$, and $50 \mathrm{wt} \%$, respectively. The changes were small at this filler loading range (20-50 wt\%). However, with the further addition of $\mathrm{hBN}$ to $60 \mathrm{wt} \%$, the thermal conductivity improved to $1.3 \mathrm{~W} \mathrm{~m}^{-1} \mathrm{~K}^{-1}$, while $80 \mathrm{wt} \%$ and $90 \mathrm{wt} \% \mathrm{hBN} / \mathrm{SEBS}$ composite films exhibited thermal conductivity of about $3 \mathrm{~W} \mathrm{~m} \mathrm{~K}^{-1}$ and $4.4 \mathrm{~W} \mathrm{~m}^{-1} \mathrm{~K}^{-1}$, respectively.

Fig. 4d shows the temperature-dependent thermal conductivity of the $95 \mathrm{wt} \% \mathrm{hBN} / \mathrm{SEBS}$ composite film. The thermal conductivity of the samples decreased as the temperature increased from $25{ }^{\circ} \mathrm{C}$ to $125^{\circ} \mathrm{C}$. Since the number of collisions that occurring between phonons increase when the temperature rises, ${ }^{\mathbf{4 0}}$ the decreased thermal conductivity could originate from the decrease in the average free path of the phonons. As shown in Fig. 4e, the thermal conductivity values demonstrated reproducible results without any change over three heating/ cooling cycles ranging from $25{ }^{\circ} \mathrm{C}$ to $125{ }^{\circ} \mathrm{C}$. This suggested good thermal stability in this temperature range.

Thermal conduction in electrically insulated materials is dominated by a phonon transferring from a particle to its adjacent particles. The polymer matrix among these particles could be compared to a "river" to cross. It was thought that building a "bridge" was an ideal way to cross the river. The bridge was composed of many boards, where one could cross the river by jumping from one board to another. Thus, the construction of "bridges", also called thermally conductive pathways, had a great effect on the heat transfer. As shown in Fig. 5a, when increasing the hBN content, more "floated wooden boards" were observed, which could slow down the jumping time and thus increase the thermal diffusivity, resulting a composite with higher thermal conductivity.

In the in-plane direction, a sudden jump happened in the thermal conductivity of the composites when they reached $40 \mathrm{wt} \% \mathrm{hBN}$ loading; this value is the percolation threshold. This also depended on the filler' orientation. ${ }^{48}$ To account for the observed behavior, molecular dynamics simulations were performed to investigate the underlying mechanisms of the enhanced thermal conductivity. To simplify the calculation process and obtain the thermal conductivity enhancement trends qualitatively, the hBN sheets that were used in the simulation had a width of $2.5 \mathrm{~nm}$ and a length of $7.5 \mathrm{~nm}$. The thermal conductivity was calculated to be $186 \mathrm{~W} \mathrm{~m}^{-1} \mathrm{~K}^{-1}$ with an rNEMD. The thermal conductivity of layered materials (including hBN) typically increased as the size increased. This 
(a)

(c)

(e)
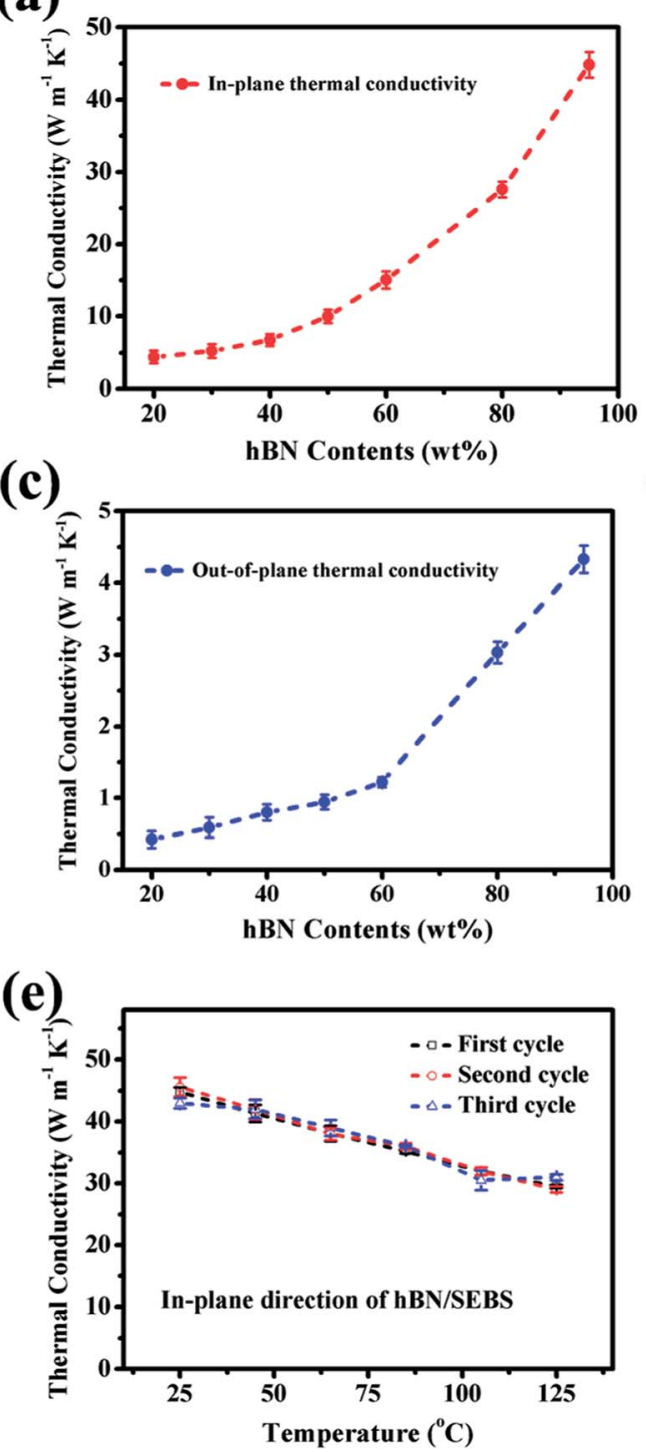

(b)

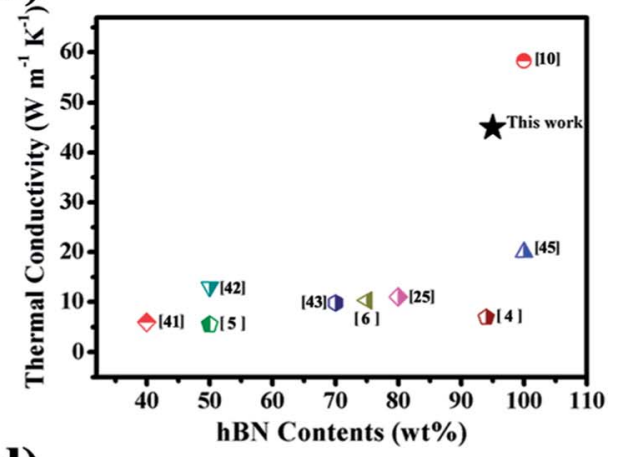

(d)

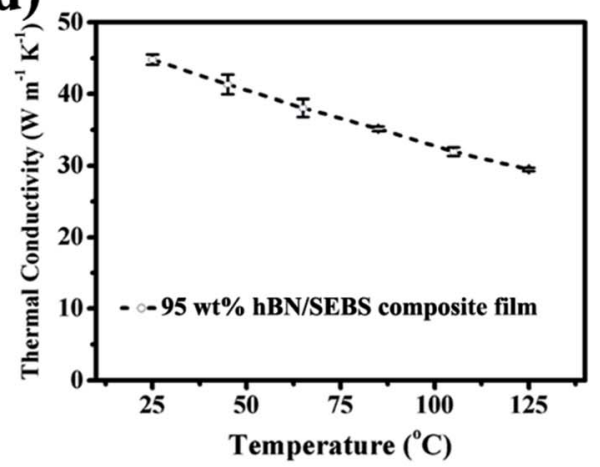

(f)

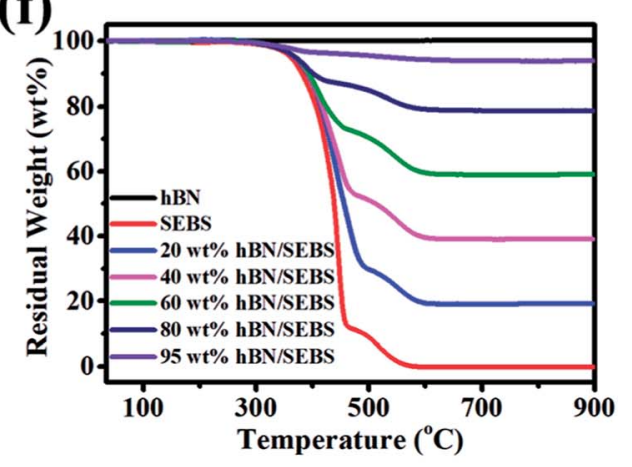

Fig. 4 (a) In-plane thermal conductivity of the hBN/SEBS composite films with various hBN loadings. (b) Thermal conductivity of the 95 wt\% $\mathrm{hBN} / \mathrm{SEBS}$ composite film and that of other hBN-filled composites reported in previous work. (c) Out-of-plane thermal conductivity of hBN/SEBS composite films with various hBN loadings. (d) Temperature dependence of thermal conductivity of the 95 wt\% hBN/SEBS composite film. (e) Thermal conductivity as a function of temperature in $95 \mathrm{wt} \% \mathrm{hBN} / \mathrm{SEBS}$ composite film for three heating cycles. (f) TGA curves of hBN, SEBS and hBN/SEBS composite films with various loadings.

Table 1 Characteristic thermal data of the SEBS matrix and the hBN/ SEBS composites

\begin{tabular}{lllll}
\hline & \multicolumn{4}{l}{ Weight loss temperature $/{ }^{\circ} \mathrm{C}$} \\
\cline { 2 - 4 } Samples & $T_{5}$ & $T_{30}$ & $T_{50}$ & \\
\hline Pure SEBS & 361.1 & 420.8 & 438.6 & $T_{\mathrm{HRI}}{ }^{a} /{ }^{\circ} \mathrm{C}$ \\
$20 \mathrm{wt} \% \mathrm{hBN} / \mathrm{SEBS}$ & 367.7 & 430.1 & 455.6 & 194.5 \\
$40 \mathrm{wt} \% \mathrm{hBN} / \mathrm{SEBS}$ & 369.0 & 437.1 & 510.0 & 200.8 \\
$60 \mathrm{wt} \% \mathrm{hBN} / \mathrm{SEBS}$ & 370.9 & 499.7 & - & - \\
$80 \mathrm{wt} \% \mathrm{hBN} / \mathrm{SEBS}$ & 371.2 & - & - & - \\
$95 \mathrm{wt} \% \mathrm{hBN} / \mathrm{SEBS}$ & 533.0 & - & - & -
\end{tabular}

${ }^{a}$ The $T_{\mathrm{HRI}}$ of the samples were calculated by eqn (1). ${ }^{38,39}$ resulted in the small-sized hBN having a smaller thermal conductivity than obtained from the experiments. Hence, the calculated thermal conductivity from the hBN-related systems did not map to the experimental results quantificationally, but only qualitatively.

The effects of the content and geometry configurations of hBN were investigated by calculating the thermal conductivity of various hBN/SEBS systems (Fig. 5c). The thermal conductivity of pure SEBS was $0.13 \mathrm{~W} \mathrm{~m}^{-1} \mathrm{~K}^{-1}$ when hBN was not present. When $10 \mathrm{wt} \% \mathrm{hBN}$ was introduced into the SEBS matrix, the thermal conductivity increased to $0.33 \mathrm{~W} \mathrm{~m}^{-1} \mathrm{~K}^{-1}$. The hBN was separated from each other by SEBS (Fig. $5 b(i)$ ). When the content of hBN increased to $30 \mathrm{wt} \%$ while the hBN was isolated in the matrix, the thermal conductivity became $0.34 \mathrm{~W} \mathrm{~m}^{-1} \mathrm{~K}^{-1}$. 
(a) hBN plates SEBS chains
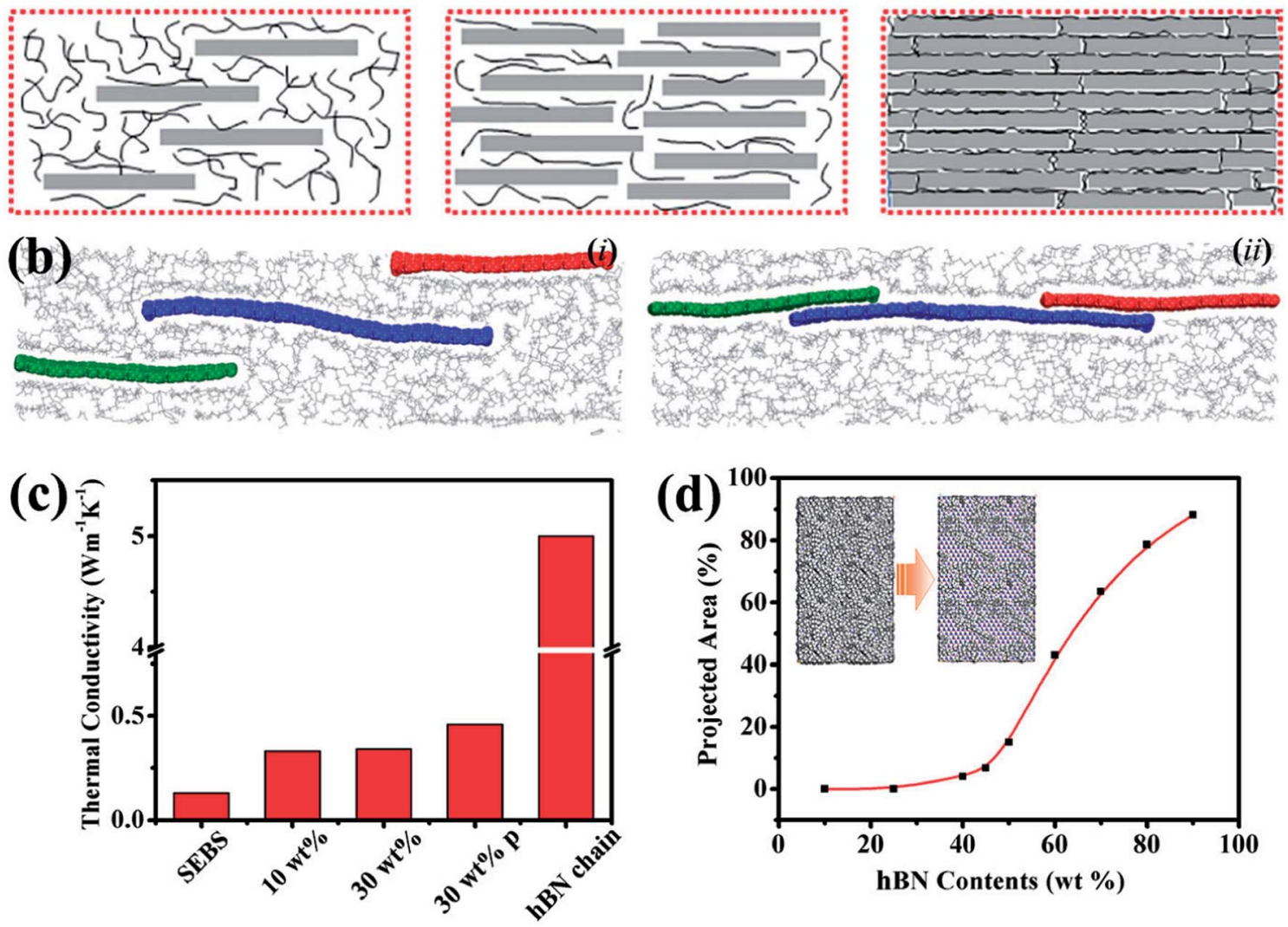

Fig. 5 (a) Schematic models of various dispersion types of hBN plates in a SEBS matrix; with increasing hBN plate contents, heat-transfer pathways were established in the matrix. (b) Molecular dynamics simulations models: (i) the heat-transfer pathways were not constructed by hBN. (ii) The heat-transfer pathways were constructed by hBN. The red, blue, and green colors present three individual hBN molecules, and the gray presents the SEBS matrix. (c) Molecular dynamics simulation for computing thermal conductivity of different structures. The 10 wt\% and $30 \mathrm{wt} \%$ represented the hBN contents. The " $\mathrm{p}$ " in "30 wt\% p" represented the formation of heat-transfer pathways. When the hBN projected area was not equal to zero, it meant that an $\mathrm{hBN}$ chain could be constructed. (d) Variations of the projected area occupied by hBN from the top-view with hBN contents, the inset presents the models from the top-view of hBN-based composites with 25 wt $\%$ and 50 wt $\%$ hBN. When the hBN content was $25 \mathrm{wt} \%$, the hBN could not overlap. When the content increased to $50 \mathrm{wt} \%$, heat-transfer pathways were established.

The difference of $0.01 \mathrm{~W} \mathrm{~m}^{-1} \mathrm{~K}^{-1}$ was within statistical error. This suggested that a simple increment of the isolated hBN in the matrix would not sufficiently enhance the thermal conductivity of the hBN/SEBS systems. Nevertheless, the hBN in the matrix had the capability of connecting to each other to form an hBN chain for thermal conduction within the experiments. Hence, a model containing a thermal conduction chain formed by the $30 \mathrm{wt} \% \mathrm{hBN}$ was constructed (Fig. $5 \mathrm{~b}(\mathrm{ii})$ ). The thermal conductivity increased markedly to $0.46 \mathrm{~W} \mathrm{~m} \mathrm{~m}^{-1} \mathrm{~K}^{-1}$. With the content remaining at $30 \mathrm{wt} \%$, the $35 \%$ enhancement of thermal conductivity indicated that the experimental observation of high thermal conductivity at high hBN content was a result of the establishment of heat-transfer networks. Since a previous study found that the heat was mainly conducted in the layered material in a composite, ${ }^{49}$ the thermal conductivity of the hBN chain could be estimated as about $5.01 \mathrm{~W} \mathrm{~m}^{-1} \mathrm{~K}^{-1}$ by calculating its volume. With continuously increasing the content of hBN to a very high content (such as $90 \mathrm{wt} \%$ ), the thermal conductivity of the hBN/SEBS system should be around the value of the hBN chain with the size configurations in this simulation. It was now clear that the addition of a small amount hBN could significantly enhance the thermal conductivity. The thermal conductivity improved by a small amount when additional hBN was present before the construction of the heattransfer networks. When the content was high enough to form heat-transfer networks, the corresponding thermal conductivity increased markedly. The possibility of forming the thermally conductive pathways by hBN was described quantitatively by calculating the corresponding relationship between the projected areas from the top-view occupied by hBN with its contents (Fig. 5d). The heat-transfer networks were established by this curve when the hBN content was greater than $40 \mathrm{wt} \%$. This was in accordance with our experimental results about the thermal conductivity. A similar phenomenon was observed in 


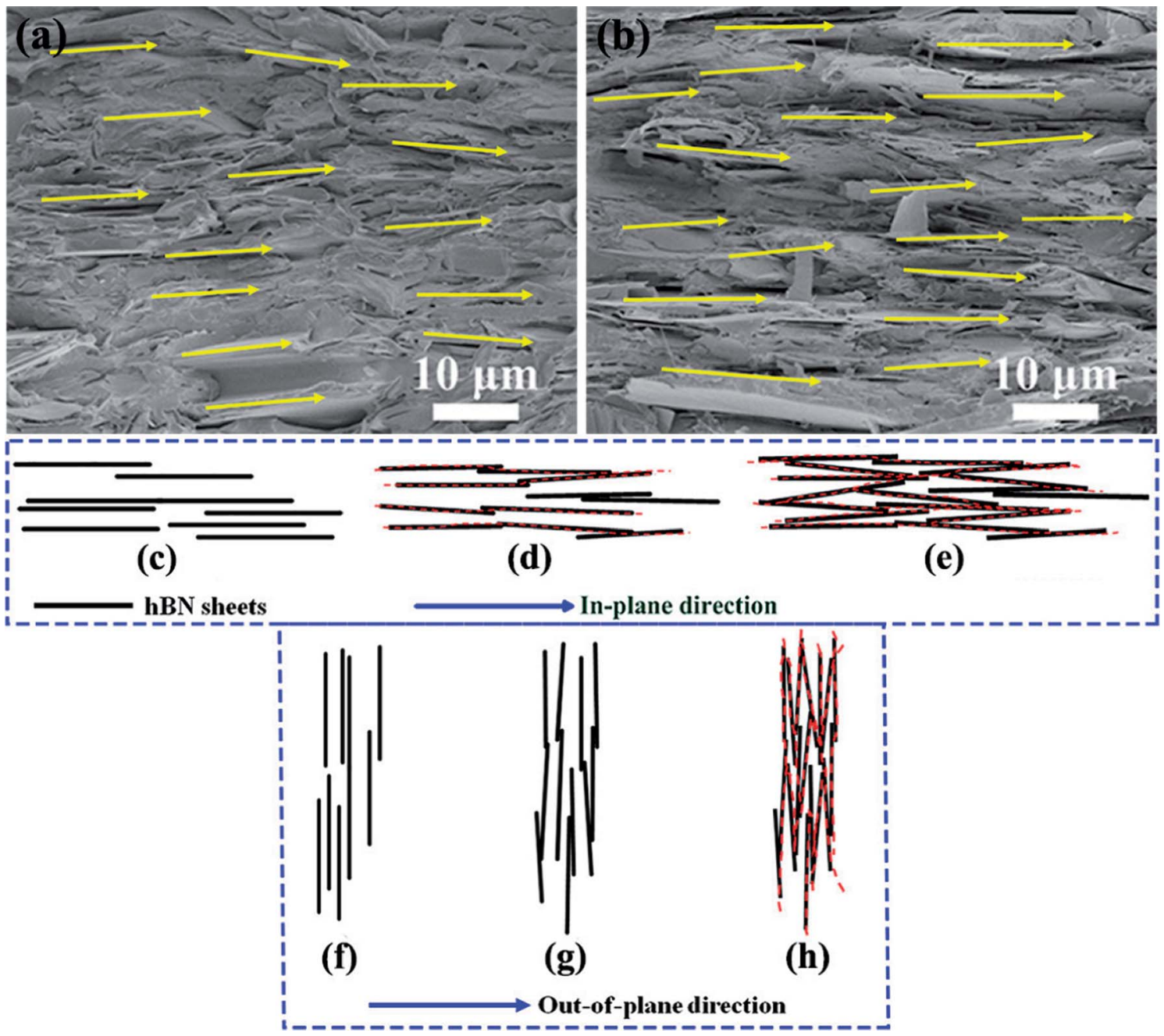

Fig. 6 Cross-sectional SEM images of the $40 \mathrm{wt} \% \mathrm{hBN} / \mathrm{SEBS}$ composite film (a) and $60 \mathrm{wt} \% \mathrm{hBN} / \mathrm{SEBS}$ composite film (b). (c and f) Schematic model of the perfectly aligned structure of hBN in the in-plane direction. Schematic models showing heat transferring along the thermally conductive pathways constructed by hBN sheets via phonons in $40 \mathrm{wt} \% \mathrm{hBN} / \mathrm{SEBS}$ composite film in the in-plane direction (d) and in the out-ofplane direction $(\mathrm{g})$. Schematic models showing heat transferring along the thermally conductive pathways constructed by hBN sheets via phonons in $60 \mathrm{wt} \% \mathrm{hBN} / \mathrm{SEBS}$ composite film in the in-plane direction (e) and in the out-of-plane direction (h).

the hBN/SEBS composites in the out-of-plane direction. However, the percolation in the out-of-plane direction was about $60 \mathrm{wt} \%$, different from $40 \mathrm{wt} \%$ in the in-plane direction.

The difference in percolation in the in-plane direction and out-of-plane direction relied on the arrangement and orientation of hBN in the composite films. Since micro-sized hBN with a $2 \mathrm{D}$ plates structure was aligned in the composite films at all hBN loadings due to the hot-compression induced alignment, the fillers preferred to form thermally conductive pathways in the in-plane direction in this structure. This could be explained by the perfectly aligned hBN being tilted over slightly in the samples. As shown in the cross-sectional SEM images of $40 \mathrm{wt} \%$ and $60 \mathrm{wt} \% \mathrm{hBN} / \mathrm{SEBS}$ composite films (Fig. 6a and b), almost all the hBN was aligned in the in-plane direction. However, these 2D sheets were tilted over slightly more or less and the tilt angle was very small (revealed by the bright yellow arrow in the figures). To explain the mechanism of constructing thermally conductive pathways, the schematic models are exhibited in Fig. $6 \mathrm{c}-\mathrm{h}$. The perfectly aligned hBN structure was shown in
Fig. $6 \mathrm{c}$ and $\mathrm{f}$. The sheets were separated from each other in the matrix, and thus there was no thermally conductive pathways formed by the $2 \mathrm{D}$ fillers. The slight tilt of hBN induced contact between two sheets and thus several thermally conductive

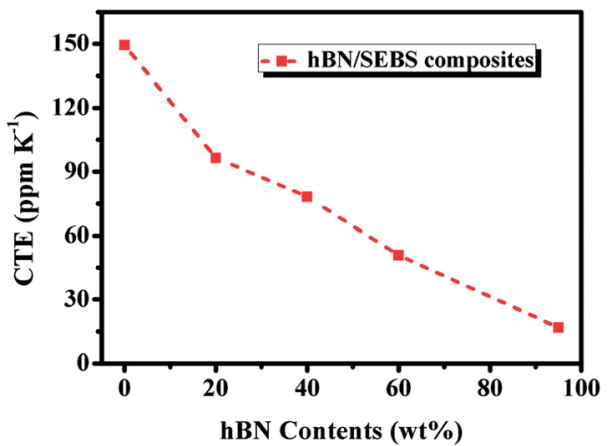

Fig. 7 CTE of the different hBN/SEBS composites as a function of hBN contents. 


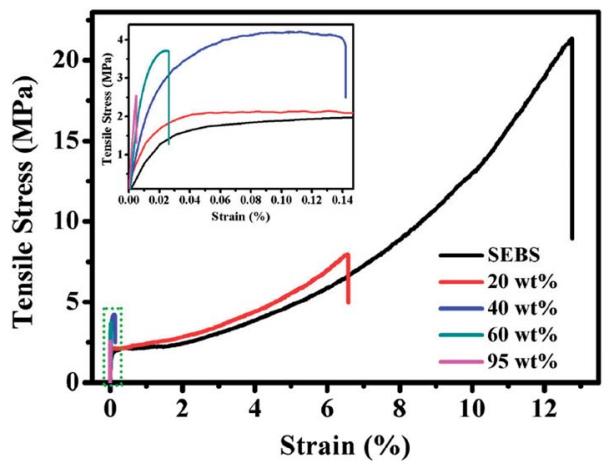

Fig. 8 Typical stress-strain plots of the hBN/SEBS composites with various hBN loadings.

pathways were initially formed, as shown in the red dotted line in Fig. 6d. However, the slight tilt of hBN was not enough to form thermally conductive pathways in the out-of-plane direction at these hBN loadings (Fig. 6g). This indicated that a small amount of tilted hBN could facilitate the formation of thermally conductive pathways in the in-plane direction, but could not achieve this goal in the out-of-plane direction. With the further addition of hBN, thermally conductive pathways were constructed in the out-of-plane direction initially (Fig. 6h), with the numbers of thermally conductive pathways increasing in the inplane direction simultaneously (Fig. 6e). This indicated that the formation of initial thermally conductive pathways needed a greater hBN content in the out-of-plane direction than that needed in the in-plane direction. Therefore, the percolation in the out-of-plane direction was higher than that in the in-plane direction theoretically. The percolation in the out-of-plane direction was about 60 wt\%, while this value was about $40 \mathrm{wt} \%$ in the in-plane direction in the hBN/SEBS composites prepared by our method. This was in accordance with the theoretical trend.

The dimensional stability of polymer composites has a great impact on the reliability of electronic devices and is indicated by CTE values. The linear CTE of hBN/SEBS composites along the alignment direction was tested by TMA. As shown in Fig. 7, the CTE values for the composites decreased with increasing the hBN loading. The CTE of pure SEBS was $149 \mathrm{ppm} \mathrm{K}^{-1}$, whereas that of the composites were $96 \mathrm{ppm} \mathrm{K} \mathrm{K}^{-1}, 78 \mathrm{ppm} \mathrm{K}{ }^{-1}, 50 \mathrm{ppm}$ $\mathrm{K}^{-1}$, and $16 \mathrm{ppm} \mathrm{K}^{-1}$ for $20 \mathrm{wt} \%, 40 \mathrm{wt} \%, 60 \mathrm{wt} \%$, and $95 \mathrm{wt} \%$ loadings, respectively. This could be ascribed to the embedding of low expansion hBN effectively restricting the mobility of the polymer chains. ${ }^{\mathbf{5 0}, 51}$ Besides, since hBN possesses an anisotropic property (the in-plane CTE of hBN is as low as $-2.7 \mathrm{ppm} \mathrm{K}^{-1}$, but the out-of-plane CTE is $\left.38 \mathrm{ppm} \mathrm{K}^{-1}\right),{ }^{51,52}$ the alignment of hBN is more effective to limit the motion of the molecular chain of SEBS, especially along the alignment direction. The negative in-plane CTE of hBN also contributed to the CTE reduction of the composites.

The mechanical properties of SEBS film and hBN/SEBS composite films with varying hBN loadings are shown in Fig. 8 and summarized in Table 2. Compared to pure SEBS film, the Young's modulus of the composites was enhanced, because the high filler-loaded and aligned hBN could efficiently resist deformation. However, the breaking stress and breaking strain were all found to decrease with increasing hBN loading. The breaking stress and breaking strain of pure SEBS were $21.4 \pm 2.1 \mathrm{MPa}$ and $12.779 \pm 3.067 \%$, respectively. These values decreased to $8.1 \pm 0.5 \mathrm{MPa}$ and $6.592 \pm 0.751 \%$ at $20 \mathrm{wt} \% \mathrm{hBN}$ loading, respectively. With the further addition of hBN, the breaking strain of the hBN/SEBS composites decreased and reached $0.142 \pm 0.017 \%, 0.026 \pm 0.003 \%$, and $0.005 \pm 0.0005 \%$ at $40 \mathrm{wt} \%, 60 \mathrm{wt} \%$, and $95 \mathrm{wt} \% \mathrm{hBN}$ loading. The corresponding breaking stress decreased slightly and reached $4.2 \pm 0.2 \mathrm{MPa}, 3.7 \pm 0.2 \mathrm{MPa}$, and $2.6 \pm 0.1 \mathrm{MPa}$, respectively. The reason for this decrease could be ascribed to the large aspect ratio of hBN and the alignment structure restricted the movement of the polymer chains, and this influence was more significant at a relatively higher filler loading. ${ }^{53}$ In addition, the concentration of stress at the hBN sheets increased at a higher $\mathrm{hBN}$ loading and led to the breaking of the composites during the stretching process. ${ }^{54}$

The heat-dissipation property of the as-made hBN/SEBS composite film was evaluated by using a CPU connected to a computer. The CPU output power was fixed at $60 \%$. The tested sample strip was $20 \mathrm{~mm}$ (length) $\times 20 \mathrm{~mm}$ (width) $\times 0.25 \mathrm{~mm}$ (thickness) and set on the same CPU for $3200 \mathrm{~s}$. The samples were heated from room temperature to ensure that the CPU temperature reached a steady state for comparison. The ambient temperature remained stable at $25{ }^{\circ} \mathrm{C}$ during the experiment. Table 3 illustrated the stable temperatures of pure SEBS and $95 \mathrm{wt} \% \mathrm{hBN} / \mathrm{SEBS}$ composites. For the SEBSembedded CPU device, the temperature of the CPU reached about $58{ }^{\circ} \mathrm{C}$. On the other hand, the $95 \mathrm{wt} \% \mathrm{hBN} / \mathrm{SEBS}$ composite film exhibited a significantly improved thermal dissipation property. After $3200 \mathrm{~s}$, the hBN/SEBS-based CPU stabilized at about $54{ }^{\circ} \mathrm{C}$. The typical temperature variation of the working CPU is shown in Fig. S2. $\dagger$ These results confirmed the excellent heat-dissipation ability of the hBN/SEBS composite film.

Table 2 Mechanical properties of SEBS film and the hBN/SEBS composite films at different hBN loadings. The average values were obtained from more than 3 samples

\begin{tabular}{lcrr}
\hline Sample & Young's modulus (MPa) & Strain-at-break (\%) & Stress-at-break (MPa) \\
\hline SEBS & $72.8 \pm 13.1$ & $12.779 \pm 3.067$ & $21.4 \pm 2.1$ \\
$20 \mathrm{wt} \% \mathrm{hBN} / \mathrm{SEBS}$ & $88.4 \pm 10.1$ & $6.592 \pm 0.751$ & $8.1 \pm 0.5$ \\
$40 \mathrm{wt} \% \mathrm{hBN} / \mathrm{SEBS}$ & $176 \pm 12$ & $0.142 \pm 0.017$ & $4.2 \pm 0.2$ \\
$60 \mathrm{wt} \% \mathrm{hBN} / \mathrm{SEBS}$ & $313 \pm 31$ & $0.026 \pm 0.003$ & $3.7 \pm 0.2$ \\
$95 \mathrm{wt} \% \mathrm{hBN} / \mathrm{SEBS}$ & $636 \pm 81$ & $0.005 \pm 0.0005$ & $2.6 \pm 0.1$
\end{tabular}


Table 3 Stable temperatures of pure SEBS and 95 wt\% hBN/SEBS composites $^{a}$

\begin{tabular}{lrrrrr}
\hline \multicolumn{7}{c}{ Stable temperature $/{ }^{\circ} \mathrm{C}$} \\
\hline$T_{\mathrm{p}}$ & 58.1 & 58.2 & 57.8 & 57.9 & 58.0 \\
$T_{\mathrm{c}}$ & 54.2 & 54.3 & 54.0 & 53.8 & 53.8 \\
$\Delta T$ & 3.9 & 3.9 & 3.8 & 4.1 & 4.2
\end{tabular}

${ }^{a} T_{\mathrm{p}}$ represents the stable temperature of pure SEBS; $T_{\mathrm{c}}$ represents the stable temperature of the $95 \mathrm{wt} \% \mathrm{hBN} / \mathrm{SEBS}$ composites; $\Delta T$ represents the decrease in stable temperature from pure SEBS to the $95 \mathrm{wt} \% \mathrm{hBN} / \mathrm{SEBS}$ composites.

\section{Conclusions}

In summary, hBN oriented in the SEBS matrix at a large range of filler loadings (0-95 wt\%) was achieved via a hot pressinginduced alignment. The as-prepared SEBS composite films exhibited a superior thermal conductivity of about $45 \mathrm{~W} \mathrm{~m}^{-1}$ $\mathrm{K}^{-1}$ at $95 \mathrm{wt} \% \mathrm{hBN}$ loading. The CTE values for the composites decreased with increasing the hBN loading. The Young's modulus of the composites was enhanced while the corresponding breaking stress and breaking strain decreased with the increasing addition of hBN loading. Based on the controlled structure in the composites at this filler loading ranges, the heat-transfer mechanism was demonstrated in detail by schematic models and molecular dynamics simulations. The percolation threshold was discovered in the in-plane (40 wt\%) and out-of-plane (60 wt\%) directions. This was instructive to study the thermal performance of composites.

\section{Conflicts of interest}

There are no conflicts of interest to declare.

\section{Acknowledgements}

This work was supported by the National Key R\&D Program of China (No. 2017YFB0406000), the Key Research Program of Frontier Science of Chinese Academy of Sciences (No. QYZDBSSW-SLH031), the Thousand Youth Talents Plan, the Postdoctoral Foundation of China (No. 2016M601905 and 2017M621855), the Natural Science Foundation of Jiangsu Province, China (No. BK20160399), the Postdoctoral Foundation of Jiangsu Province (No. 1601065B), and the Science and Technology Project of Nanchang (2017-SJSYS-008).

\section{References}

1 H. Zhu, Y. Li, Z. Fang, J. Xu, F. Cao, J. Wan, C. Preston, B. Yang and L. Hu, ACS Nano, 2014, 8, 3606-3613.

2 W. Meng, Y. Huang, Y. Fu, Z. Wang and C. Zhi, J. Mater. Chem. C, 2014, 2, 10049-10061.

3 J. Chen, X. Huang, Y. Zhu and P. Jiang, Adv. Funct. Mater., 2017, 27, 1604754.

4 X. Zeng, L. Ye, S. Yu, H. Li, R. Sun, J. Xu and C. P. Wong, Nanoscale, 2015, 7, 6774-6781.
5 Z. Kuang, Y. Chen, Y. Lu, L. Liu, S. Hu, S. Wen, Y. Mao and L. Zhang, Small, 2015, 11, 1655-1659.

6 Y. Xu and D. D. L. Chung, Compos. Interfaces, 2000, 7, 243256.

7 Y. Xu, D. D. L. Chung and C. Mroz, Composites, Part A, 2001, 32, 1749-1757.

8 J. Xia, J. Li, G. Zhang, X. Zeng, F. Niu, H. Yang, R. Sun and C. Wong, Composites, Part A, 2016, 80, 21-27.

9 C. P. Wong and R. S. Bollampally, J. Appl. Polym. Sci., 1999, 74, 3396-3403.

10 L. Fu, T. Wang, J. H. Yu, W. Dai, H. Sun, Z. Liu, R. Sun, N. Jiang, A. Yu and C. T. Lin, 2D Mater., 2017, 4, 025047.

11 D. Golberg, Y. Bando, Y. Huang, T. Terao, M. Mitome, C. Tang and C. Zhi, ACS Nano, 2010, 4, 2979-2993.

12 C. Zhi, Y. Bando, T. Terao, C. Tang, H. Kuwahara and D. Golberg, Adv. Funct. Mater., 2009, 19, 1857-1862.

13 W. L. Song, P. Wang, L. Cao, A. Anderson, M. J. Meziani, A. J. Farr and Y. P. Sun, Angew. Chem., Int. Ed., 2012, 51, 6498-6501.

14 F. Yuan, W. C. Jiao, F. Yang, W. B. Liu, Z. H. Xu and R. G. Wang, RSC Adv., 2017, 7, 43380-43389.

15 O. S. Kwon, D. Lee, S. P. Lee, Y. G. Kang, N. C. Kim and S. H. Song, RSC Adv., 2016, 6, 59970-59975.

16 A. Permal, M. Devarajan, H. L. Hung, T. Zahner, D. Lacey and K. Ibrahim, J. Mater. Sci., 2016, 51, 7415-7426.

17 F. F. Wang, Y. M. Yao, X. L. Zeng, T. Huang, R. Sun, J. B. Xu and C. P. Wong, RSC Adv., 2016, 6, 41630-41636.

18 X. Zeng, J. Sun, Y. Yao, R. Sun, J. Xu and C. P. Wong, ACS Nano, 2017, 11, 5167-5178.

19 X. Huang, C. Zhi, P. Jiang, D. Golberg, Y. Bando and T. Tanaka, Adv. Funct. Mater., 2013, 23, 1824-1831.

20 Z. Lin, Y. Liu, S. Raghavan, K. S. Moon, S. K. Sitaraman and C. P. Wong, ACS Appl. Mater. Interfaces, 2013, 5, 7633-7640.

21 H. Shen, J. Guo, H. Wang, N. Zhao and J. Xu, ACS Appl. Mater. Interfaces, 2015, 7, 5701-5708.

22 C. Yuan, B. Duan, L. Li, B. Xie, M. Huang and X. Luo, ACS Appl. Mater. Interfaces, 2015, 7, 13000-13006.

23 H. S. Lim, J. W. Oh, S. Y. Kim, M. J. Yoo, S. D. Park and W. S. Lee, Chem. Mater., 2013, 25, 3315-3319.

24 X. Zeng, Y. Yao, Z. Gong, F. Wang, R. Sun, J. Xu and C. P. Wong, Small, 2015, 11, 6205-6213.

25 T. Morishita and H. Okamoto, ACS Appl. Mater. Interfaces, 2016, 8, 27064-27073.

26 H.-B. Cho, T. Nakayama, Y. Tokoi, S. Endo, S. Tanaka, T. Suzuki, W. Jiang, H. Suematsu and K. Niihara, Compos. Sci. Technol., 2010, 70, 1681-1686.

27 J. Gu, C. Liang, J. Dang, W. Dong and Q. Zhang, RSC Adv., 2016, 6, 35809-35814.

28 X. Yang, L. Tang, Y. Guo, C. Liang, Q. Zhang, K. Kou and J. Gu, Composites, Part A, 2017, 101, 237-242.

29 X. Yang, Y. Guo, X. Luo, N. Zheng, T. Ma, J. Tan, C. Li, Q. Zhang and J. Gu, Compos. Sci. Technol., 2018, 164, 59-64.

30 Y. Li, G. Xu, Y. Guo, T. Ma, X. Zhong, Q. Zhang and J. Gu, Composites, Part A, 2018, 107, 570-578.

31 Y. Yao, X. Zeng, F. Wang, R. Sun, J. Xu and C. P. Wong, Chem. Mater., 2016, 28, 1049-1057. 
32 C. Yu, J. Zhang, Z. Li, W. Tian, L. Wang, J. Luo, Q. Li, X. Fan and Y. Yao, Composites, Part A, 2017, 98, 25-31.

33 R. M. Erb, R. Libanori, N. Rothfuchs and A. R. Studart, Science, 2012, 335, 199-204.

34 S. Plimpton, J. Comput. Phys., 1995, 117, 1-19.

35 S. J. Stuart, A. B. Tutein and J. A. Harrison, J. Chem. Phys., 2000, 112, 6472-6486.

36 A. Kınacı, J. B. Haskins, C. Sevik and T. Çağın, Phys. Rev. B, 2012, 86, 115410.

37 F. Müller-Plathe, J. Chem. Phys., 1997, 106, 6082-6085.

38 Y. Tang, W. Dong, L. Tang, Y. Zhang, J. Kong and J. Gu, Compos. Commun., 2018, 8, 36-41.

39 J. Gu, W. Dong, Y. Tang, Y. Guo, L. Tang, J. Kong, S. Tadakamalla, B. Wang and Z. Guo, J. Mater. Chem. C, 2017, 5, 6929-6936.

40 S. Berber, Y. K. Kwon and D. Tománek, Phys. Rev. Lett., 2000, 84, 4613-4616.

41 X. B. Wang, Q. Weng, X. Wang, X. Li, J. Zhang, F. Liu, X. F. Jiang, H. Guo, N. Xu, D. Golberg and Y. Bando, ACS Nano, 2014, 8, 9081-9088.

42 R. C. Zhang, D. Sun, A. Lu, S. Askari, M. Macias-Montero, P. Joseph, D. Dixon, K. Ostrikov, P. Maguire and D. Mariotti, ACS Appl. Mater. Interfaces, 2016, 8, 1356713572.

43 J. Yu, H. Mo and P. Jiang, Polym. Adv. Technol., 2015, 26, 514520 .
44 T. Morishita and H. Okamoto, ACS Appl. Mater. Interfaces, 2016, 8, 27064-27073.

45 J. C. Zheng, L. Zhang, A. V. Kretinin, S. V. Morozov, Y. B. Wang, T. Wang, X. Li, F. Ren, J. Zhang, C. Y. Lu, J. C. Chen, M. Lu, H. Q. Wang, A. K. Geim and K. S. Novoselov, 2D Mater., 2016, 3, 011004.

46 L. Fu, T. Wang, J. Yu, W. Dai, H. Sun, Z. Liu, R. Sun, N. Jiang, A. Yu and C. T. Lin, 2D Mater., 2017, 4, 025047.

47 X. Zeng, L. Ye, S. Yu, H. Li, R. Sun, J. Xu and C. P. Wong, Nanoscale, 2015, 7, 6774-6781.

48 Z. Kuang, Y. Chen, Y. Lu, L. Liu, S. Hu, S. Wen, Y. Mao and L. Zhang, Small, 2015, 11, 1655-1659.

49 L. Hu, T. Desai and P. Keblinski, J. Appl. Phys., 2011, 110, 033517.

50 C. Zhi, Y. Bando, C. Tang, H. Kuwahara and D. Golberg, Adv. Mater., 2009, 21, 2889-2893.

51 Z. Lin, Y. Liu, S. Raghavan, K. S. Moon, S. K. Sitaraman and C. P. Wong, ACS Appl. Mater. Interfaces, 2013, 5, 7633-7640. 52 X. Zeng, Y. Yao, Z. Gong, F. Wang, R. Sun, J. Xu and C. P. Wong, Small, 2015, 11, 6205-6213.

53 J. T. Kim, B. K. Kim, E. Y. Kim, S. H. Kwon and H. M. Jeong, Eur. Polym. J., 2013, 49, 3889-3896.

54 X. Zhao, Q. Zhang, D. Chen and P. Lu, Macromolecules, 2010, 43, 2357-2363. 